\title{
Deep convective clouds at the tropopause
}

\author{
H. H. Aumann ${ }^{1}$, S. G. DeSouza-Machado ${ }^{2}$, and A. Behrangi ${ }^{1}$ \\ ${ }^{1}$ California Institute of Technology, Jet Propulsion Laboratory, CA, USA \\ ${ }^{2}$ Department of Physics, University of Maryland, Baltimore County, Baltimore, MD, USA \\ Received: 24 April 2010 - Published in Atmos. Chem. Phys. Discuss.: 2 July 2010 \\ Revised: 4 January 2011 - Accepted: 24 January 2011 - Published: 11 February 2011
}

\begin{abstract}
Data from the Atmospheric Infrared Sounder (AIRS) on the EOS Aqua spacecraft each day show tens of thousands of Cold Clouds (CC) in the tropical oceans with $10 \mu \mathrm{m}$ window channel brightness temperatures colder than $225 \mathrm{~K}$. These clouds represent a mix of cold anvil clouds and Deep Convective Clouds (DCC). This mix can be separated by computing the difference between two channels, a window channel and a channel with strong $\mathrm{CO}_{2}$ absorption: for some cold clouds this difference is negative, i.e. the spectra for some cold clouds are inverted. We refer to cold clouds with spectra which are more than $2 \mathrm{~K}$ inverted as DCCi2. Associated with DCCi2 is a very high rain rate and a local upward displacement of the tropopause, a cold "bulge", which can be seen directly in the brightness temperatures of AIRS and Advanced Microwave Sounding Unit (AMSU) temperature sounding channels in the lower stratosphere. The very high rain rate and the local distortion of the tropopause indicate that DCCi2 objects are associated with severe storms. Significant long-term trends in the statistical properties of DCCi2 could be interesting indicators of climate change. While the analysis of the nature and physical conditions related to DCCi2 requires hyperspectral infrared and microwave data, the identification of DCCi2 requires only one good window channel and one strong $\mathrm{CO}_{2}$ sounding channel. This suggests that improved identification of severe storms with future advanced geostationary satellites could be accomplished with the addition of one or two narrow band channels.
\end{abstract}

Correspondence to: $\mathrm{H}$. H. Aumann (aumann@jpl.nasa.gov)

\section{Introduction}

Inspection of Atmospheric Infrared Sounder (AIRS, Aumann et al., 2003) spectra shows the expected absorption features of water, carbon dioxide and ozone relative to spectral regions of low atmospheric opacity (window areas) in almost all spectra, including those with heavy cloud cover. However, for about $1 \%$ of the spectra in the tropical oceans $\left(30^{\circ} \mathrm{S}-30^{\circ} \mathrm{N}\right)$ the spectra are inverted: the strong $\mathrm{CO}_{2} \mathrm{ab}-$ sorption near $14 \mu \mathrm{m}$, the strong water vapor absorption near $6 \mu \mathrm{m}$ and ozone absorption in the $10 \mu \mathrm{m}$ area are seen in emission relative to cold cloud tops in the $8-12 \mu \mathrm{m}$ atmospheric window channels. Negative brightness temperature differences between the $11 \mu \mathrm{m}$ window and $6.7 \mu \mathrm{m}$ water channel were first noted by Ackerman (1996). Schmetz et al. (1997) noted their association with severe thunderstorms and first attributed it to Overshooting Convection (OC). Conceptually, OC has the potential to force water vapor into the lower stratosphere where it emits at the warmer stratospheric temperature. Romps and Kuang (2009) defined overshooting cloud tops as clouds with brightness temperature colder than the monthly mean tropopause temperature climatology at that location, as derived from reanalysis of the National Centers for Environmental Prediction (NCEP) (Kalnay et al., 1996). Gettelman et al. (2002) found that "about $0.5 \%$ of the [cold] clouds appear to be colder than the mean tropopause". Others have used the reanalysis pertaining to the time and location of the observation to identify the tropopause. The relatively coarse temporal, spatial and vertical resolution of the reanalysis make the accuracy of the calculated height of the tropopause uncertain (Liu and Zipser, 2005), particularly in the presence of strong convection. What appears as OC and penetration into the stratosphere, may actually be related to the difference between the height of the tropopause under average conditions and strong convection conditions. The

Published by Copernicus Publications on behalf of the European Geosciences Union. 
objective of our paper is to use AIRS hyperspectral data to gain new insights into properties of these cold cloud tops.

\section{Data}

AIRS data together with data from the Advanced Microwave Sounder Unit (AMSU, Lambrigtsen, 2003) and the Advanced Microwave Scanning Radiometer for EOS (AMSRE, Imaoka et al., 2007) are used in the present study. AIRS, AMSU and AMSRE were launched in May 2002 on the EOS Aqua satellite into a $705 \mathrm{~km}$ altitude sun-synchronous, $98^{\circ}$ inclination circular orbit. The 01:30 p.m. ascending node, in the following referred to as the "day" overpass, and a corresponding 01:30 a.m. "night" overpass on the descending part of each orbit, are actively maintained. The orbit period is $98.99 \mathrm{~min}$ and, since the orbit is sun-synchronous, consecutive orbits are separated by $2760 \mathrm{~km}$ at the equator. More than seven years of AIRS, AMSU and AMSRE data are now available. The absolute calibration at the $200 \mathrm{mK}$ level and stability at the better than $10 \mathrm{mK} /$ year level have been validated using the sea surface temperatures (Aumann et al., 2006). The validation of the radiometric accuracy and stability at the extremely cold temperatures relevant for the study of cold cloud tops used Dome Concordia data in Antarctica (Walden et al., 2006; Elliott et al., 2007). AMSU is a 15 channel microwave radiometer, with 12 of the 15 channels centered on the $57 \mathrm{GHz}$ oxygen line. The AMSU data system is synchronized with AIRS and covers the same crosstrack swath. AMSRE is a conical scanning passive microwave imaging radiometer. The AMSRE rain rates, measured within minutes of the AIRS data, are available each day averaged on a $0.25^{\circ}$ grid, i.e., approximately on a $28 \mathrm{~km}$ scale, separately for day and night orbits. Data from AIRS and AMSU are available from the GES-DISC at GSFC since September 2002. The AMSRE rain rates (Wilheit et al., 2003) since September 2002 were obtained from $\mathrm{ftp} / / /$ rain.atmos.colostate.edu/RAINMAP/data/amsre/. Unlike AIRS and AMSU data, which are calibrated radiances and brightness temperatures (level 1b), the AMSRE rain rates used here are based on a level 3 (gridded data) product.

AIRS is a hyperspectral infrared sounder which covers the 650 to $2665 \mathrm{~cm}^{-1}$ region of the thermal infrared spectrum with 2378 spectral channels. The AIRS footprint subtends an angle of $1.1^{\circ}$ (full width at $1 / 2$ peak), corresponding to a $13 \mathrm{~km}$ footprint at nadir. The footprints are scanned $\pm 49.5^{\circ}$ cross-track, resulting in a $1650 \mathrm{~km}$ wide swath with 90 footprints, i.e. the average footprint diameter is $18 \mathrm{~km}$. The AIRS data are saved in "granules" of six minute duration. Each granule contains 135 scan lines with $90 \times 135=12150$ spectra (one spectrum per footprint). Associated with each $3 \times 3$ group of AIRS spectra are nearly simultaneous AMSU measurements with a $45 \mathrm{~km}$ diameter footprint at nadir. Figure 1a shows a $90 \times 135$ pixel image of the brightness temperature in the $1231 \mathrm{~cm}^{-1}$ window channel, bt1231, from a typi-

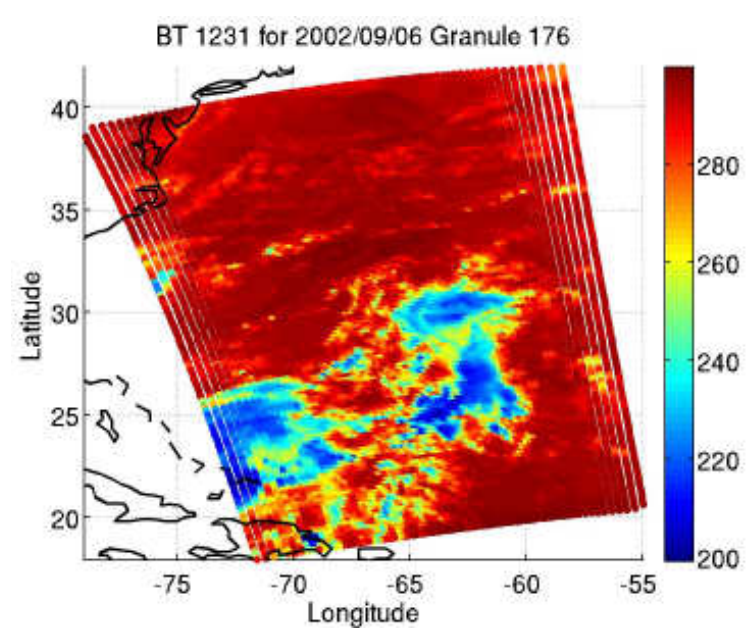

Fig. 1a. This figure shows the brightness temperature in the $1231 \mathrm{~cm}^{-1}$ window channel for a typical tropical ocean AIRS data granule.

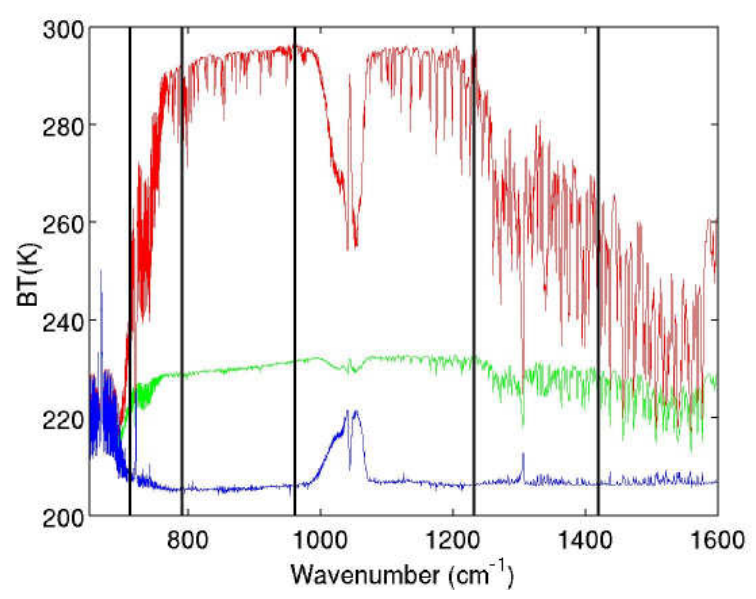

Fig. 1b. This figure shows average spectra for clear (red), high clouds (green) and inverted spectra (blue) from the data on the left. The lines indicate the approximate position of five key channels used in the analysis.

cal tropical Atlantic granule, granule 176 from 6 September 2002. The brightness temperature is shown color encoded between $199 \mathrm{~K}$ and $300 \mathrm{~K}$. Of the 12150 spectra $(90 \times 135)$ in the granule, $5016(41 \%)$ are from scenes where the observed bt1231 agrees with the expected value based on the sea surface temperature forecast by NCEP within $2 \mathrm{~K}$, i.e. these scenes are relatively cloud free. The average clear spectrum between 650 and $1600 \mathrm{~cm}^{-1}$ is shown in red in Fig. 1b. For 600 pixels (5\%) bt 1231 is between $225 \mathrm{~K}$ and $240 \mathrm{~K}$, indicating the start of deep convection with moderately high clouds. These pixels are shown in light blue in Fig. 1a and the corresponding average spectrum is shown in green in Fig. 1b. Embedded in regions of high clouds are some extremely cold cloud tops (dark blue in Fig. 1a). For 
73 pixels $(0.6 \%$ for this granule) bt $1231<210 \mathrm{~K}$, with the average spectrum shown in blue in Fig. 1b. The ozone region (near $1050 \mathrm{~cm}^{-1}$ ), the $\mathrm{CO}_{2}$ lines below $780 \mathrm{~cm}^{-1}$, the $\mathrm{CH}_{4}$ lines centered near $1305 \mathrm{~cm}^{-1}$, and the water lines between 1300 and $1600 \mathrm{~cm}^{-1}$ are now warmer than the window channels, i.e. they are inverted from the clear sky case.

Data used for our study were collected from every 5 th day between 1 September 2002 and 31 August 2009 in the tropical oceans $\left(30^{\circ} \mathrm{S}\right.$ to $\left.30^{\circ} \mathrm{N}\right)$ and divided into three subsets. For the first set we identified cloud-free spectra, typically 25000 each day, at all scan angles. In the second set we randomly collected near nadir spectra, typically 3500 each day in the tropical oceans. This set, consisting of 1.7 million spectra, was used to generate scatter diagrams. For the third set we collected all objects with brightness temperatures colder than $225 \mathrm{~K}$ in the $1231 \mathrm{~cm}^{-1}$ atmospheric window channel, i.e. cold clouds, at all scan angles. This third set typically consisted of between 15000 and 20000 spectra each day. The three sets allow us to contrast clear, random (i.e. typically cloudy) and very cloudy data. For the evaluation of spectral properties and comparison with model calculations we used the set of five of AIRS channels at $712 \mathrm{~cm}^{-1}, 790 \mathrm{~cm}^{-1}, 961 \mathrm{~cm}^{-1}, 1231 \mathrm{~cm}^{-1}$ and $1419 \mathrm{~cm}^{-1}$, highlighted as vertical lines in Fig. 1b. We refer to these channels and their brightness temperatures as bt712, bt790, etc. The bt790, bt961 and bt1231 channels are window channels in areas of weak water continuum absorption. The bt712 and bt1419 channels are in areas of strong $\mathrm{CO}_{2}$ and water vapor absorption, respectively. The measurements at these cold temperatures require very high instrument sensitivity, in particular if channel differences are used. The Noise Equivalent delta Temperature (NEdT) is a measure of the uncertainty in the brightness temperature in a single measurement. It is commonly quoted for a reference temperature at $280 \mathrm{~K}$. For example for the $1231 \mathrm{~cm}^{-1}$ channel, NEdT280 $=0.05 \mathrm{~K}$; however for a much colder scene, e.g. at $200 \mathrm{~K}, \mathrm{NEdT} 200=0.31 \mathrm{~K}$. The effective noise for difference measurements is amplified, i.e. the standard deviation of DT = bt 1231-bt712 at $200 \mathrm{~K}$ due to measurement noise alone is close to $0.5 \mathrm{~K}$. We will also use AIRS temperature sounding channels at 679.9 and $668.2 \mathrm{~cm}^{-1}$ and AMSU channels 9 and 14 to infer temperatures in the lower stratosphere.

\subsection{Spectral characterization}

Figure $2 \mathrm{a}$ shows the scatter diagram of DT vs. bt1231 for 8254 spectra with bt $1231<225 \mathrm{~K}$ from the nighttime tropical oceans from 6 September 2002. In this data set $1 \%$ of the spectra had DT less than $-10 \mathrm{~K}$, the smallest DT was $-12.8 \mathrm{~K}$. Figure $3 \mathrm{a}$ shows a scatter diagram of $\mathrm{DC}=\mathrm{bt} 961-$ bt790 vs. DT for the same data as Fig. 2a. Model calculations (Sect. 3) and physical interpretations of DT and DC (Sect. 4) are used to gain insight into the composition of the cloud tops and their location relative to the tropopause. The red lines in the two figures are the scatter diagram ridge lines, which highlight the most likely functional dependence of the two variables in the scatter diagrams. They are generated by dividing the $\mathrm{x}$-axis into $\mathrm{n}$ equal width bins, where each bin is characterized by a mean, $\mathrm{xm}$, a standard deviation, sd, and the number of points in the bin, N. The ridge lines connect the mean values of the bins (red circles). The Probable Error of the mean for each bin, $\mathrm{PE}=\mathrm{sd} / \sqrt{ } \mathrm{N}$, provides an indication of the uncertainty of the ridge line. In Fig. 3a this is shown as the two lines connecting the $\mathrm{xm}+\mathrm{PE}$ and $\mathrm{xm}-\mathrm{PE}$ values for the bins. Figure $2 \mathrm{~b}$ shows the scatter diagram derived from simulations, which will be described in Section 3 in conjunction with model calculations. Figure $3 b$ shows the corresponding scatter diagram derived from the simulations. The profiles used for the model runs match the mean, but not the dispersion of real tropical spectra, i.e. the model calculation included relatively rare cases. This gives the misleading impression that the model results are more dispersed than the observations.

\subsection{Frequency of cold clouds}

The database created by the random nadir spectra was used to calculate mean properties of $\mathrm{CC}$ for various thresholds. The frequency of occurrence is defined as the number of spectra which pass a threshold divided by the total number of spectra in a given area, expressed as percent. There are large regional differences between the Western Tropical Pacific (WTP, defined here as the region between latitude $15^{\circ} \mathrm{S}$ and $15^{\circ} \mathrm{N}$, longitude $100^{\circ} \mathrm{E}$ to $180^{\circ} \mathrm{E}$ ) and tropical ocean (TO) exclusive of the WTP. We also separated day and night data. Results are summarized in Table 1.

\subsection{Temperature structure related to cold clouds}

In the presence of high cloud overcast conditions, characterized by bt $1231<225 \mathrm{~K}$, it is difficult to measure the temperature structure near the tropopause in the thermal IR or with $57 \mathrm{GHz}$ microwave channels. In the IR this is due to scattering by the cloud particles for channels with clear sky weighting functions at or below the cloud top height. In the microwave this is due to the presence of cloud liquid water for sounding channels at or below the cloud top height. However, we can use AIRS and AMSU temperature sounding channels with weighting functions peaking well above the clouds to evaluate the lapse rate in the lower stratosphere, and thereby infer conditions near the tropopause. The $668.2 \mathrm{~cm}^{-1}$ (bt668.2) and $679.9 \mathrm{~cm}^{-1}$ (bt679.9) AIRS channels reach optical depth unity near 2 and $40 \mathrm{hPa}$, respectively. Figure 4a shows the ridge lines and ridge line uncertainties for the scatter diagram of the temperature at $2 \mathrm{hPa}$ and $40 \mathrm{hPa}$ as a function of bt1231 for the random nadir night tropical ocean data (from every 5 th day between 1 September 2002 and 31 August 2009 with 850000 spectra). As we go from clear conditions (bt1231 $=300 \mathrm{~K}$ ) to about bt1231 $=280 \mathrm{~K}$ (likely low marine stratus) the temperature 

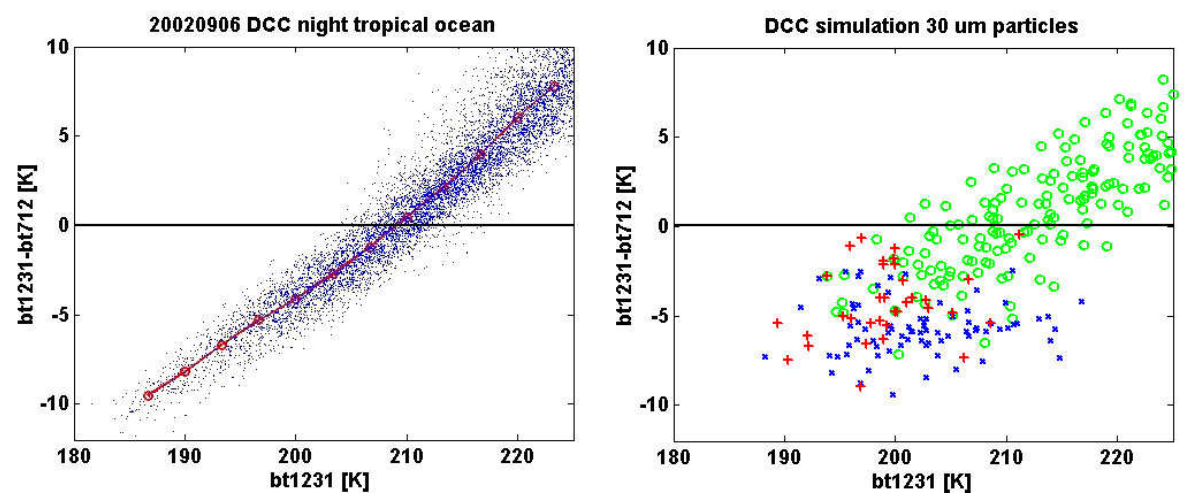

Fig. 2. bt1231-bt712 (DT) vs. bt1231 for spectra with bt1231<225 K, (a) shows the observations from one day (6 September 2002, $01: 30$ a.m. overpasses), (b) shows the results of the DCC simulations: blue $(\mathrm{x})=$ more than $5 \mathrm{hPa}$ above, red $(+)=$ within $5 \mathrm{hPa}$ of, and green $(\mathrm{o})=$ more than $5 \mathrm{hPa}$ below the tropopause of the model atmosphere.
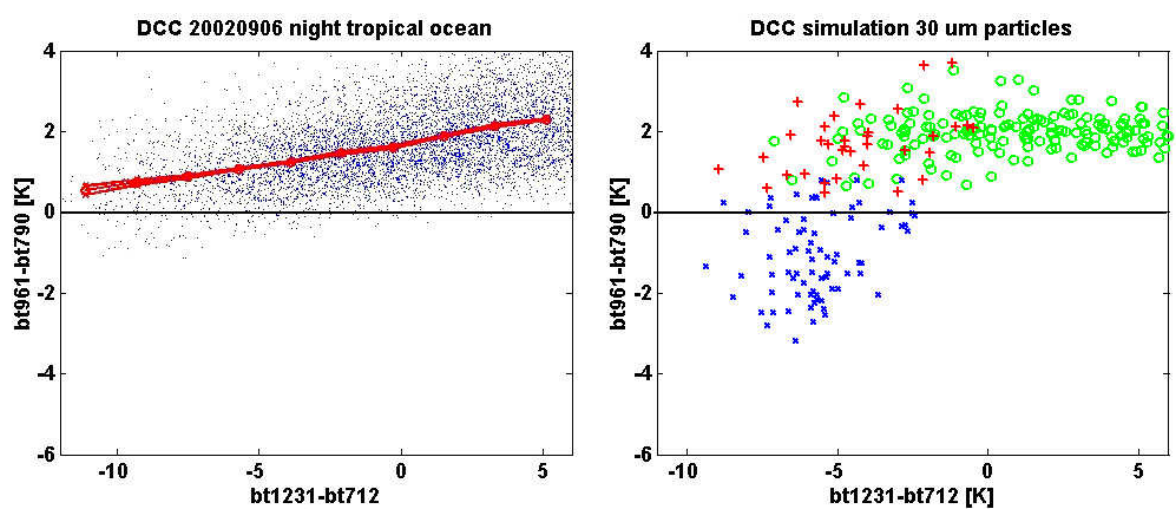

Fig. 3. bt961-bt790 (DC) vs bt1231-bt712 (DT) for spectra with bt1231<225 K, (a) from the same data used in Fig. 2a. The three lines indicate the PE of the ridge line. (b) Model results on the same scale: blue $(\mathrm{x})=$ more than $5 \mathrm{hPa}$ above, red $(+)=$ within $5 \mathrm{hPa}$ of, and green (o) $=$ more than $5 \mathrm{hPa}$ below the tropopause of the model atmosphere.

of the $679.9 \mathrm{~cm}^{-1}$ channel warms from $211.3 \mathrm{~K}$ to $212.3 \mathrm{~K}$. It then levels out to $211.7 \mathrm{~K}$ between $230 \mathrm{~K}<$ bt $1231<260 \mathrm{~K}$ (mixed clear and cloudy). As the cloud top temperature drops from $230 \mathrm{~K}$ to $190 \mathrm{~K}$ in the presence of increasingly strong convection, the $40 \mathrm{hPa}$ temperature drops to $210 \mathrm{~K}$. The opposite reaction to strong convection is seen at $2 \mathrm{hPa}$, although the effect is smaller. This surprising effect is seen in the AMSU brightness temperatures as well. There are no exact equivalent channels from AIRS and AMSU, but AMSU\#14 and AMSU\#9 also reach optical depth unity near $2 \mathrm{hPa}$ and near $50 \mathrm{hPa}$, respectively, albeit with considerably broader weighting functions than the corresponding AIRS channels. Figure $4 \mathrm{~b}$, which shows the ridge line of the scatter diagrams of AMSU\#14 and AMSU\#9 as function of bt1231 from the same data set as Fig. 4a, shows the same change in the lower stratosphere in the presence of cold clouds as the AIRS data. The numerical temperature differences between AMSU and AIRS brightness temperatures at nominally the same pressure levels are due to narrower width of the AIRS weighting functions.

\subsection{Rain rate}

We use the rain rate measured by AMSRE to evaluate the correlation between rain rate and cold clouds. Since AMSRE and AIRS are on the same spacecraft, cold clouds identified with AIRS and the rain rates measured with AMSRE are time coincident within minutes. The measurements are not exactly simultaneous because AIRS is $\pm 49^{\circ}$ cross-track scanning perpendicular to the spacecraft ground track, while AMSRE uses a forward looking $47^{\circ}$ conical scan. Figure 5 shows a scatter diagram ridge line and PE of the rain rate (connected by the solid lines) as function of DT. The mean rain rate for clouds with $0<\mathrm{DT}<5 \mathrm{~K}$ is about $1 \mathrm{~mm} / \mathrm{hr}$. The mean rain rate increases rapidly for $\mathrm{DT}<0 \mathrm{~K}$, and even faster at DT $<-5 \mathrm{~K}$. Since the AMSRE rain rate refers to the average in a $28 \mathrm{~km}$ grid, the rain rate in the (cross-track averaged) $18 \mathrm{~km}$ AIRS Field of View (FOV) could be significantly larger. There is considerable scatter in the rain rate as function of DT. Shown in Fig. 5 as dashed lines are the 16 and $84 \%$ tile values of the data within each DT bin. Table 2 
Table 1. Summary of the frequency distribution of cold clouds with AIRS.

\begin{tabular}{lrrrr}
\hline & $\begin{array}{r}\text { Day TO } \\
\text { frequency [\%] }\end{array}$ & $\begin{array}{r}\text { Night TO } \\
\text { frequency [\%] }\end{array}$ & $\begin{array}{r}\text { Day WTP } \\
\text { frequency [\%] }\end{array}$ & $\begin{array}{r}\text { Night WTP } \\
\text { frequency [\%] }\end{array}$ \\
\hline window $<260 \mathrm{~K}$ & 9.78 & 8.37 & 16.62 & 17.3 \\
window $<250 \mathrm{~K}$ & 7.43 & 5.93 & 13.12 & 12.78 \\
window $<235 \mathrm{~K}$ & 4.77 & 3.80 & 9.23 & 8.74 \\
window $<225 \mathrm{~K}$ & 3.34 & 2.84 & 6.67 & 6.96 \\
window $<215 \mathrm{~K}$ & 1.31 & 1.44 & 3.32 & 3.58 \\
window $<210 \mathrm{~K}$ & 0.39 & 0.69 & 1.97 & 2.41 \\
\hline window minus $\mathrm{H}_{2} \mathrm{O}<0 \mathrm{~K}$ & 0.72 & 0.92 & 1.87 & 2.23 \\
window minus $\mathrm{H}_{2} \mathrm{O}<-2 \mathrm{~K}$ & 0.36 & 0.54 & 1.02 & 1.31 \\
window minus $\mathrm{H}_{2} \mathrm{O}<-4 \mathrm{~K}$ & 0.11 & 0.26 & 0.36 & 0.52 \\
window minus $\mathrm{H}_{2} \mathrm{O}<-6 \mathrm{~K}$ & 0.02 & 0.06 & 0.10 & 0.17 \\
\hline window minus $\mathrm{CO}_{2}<0 \mathrm{~K}$ & 0.63 & 0.87 & 1.45 & 2.13 \\
window minus $\mathrm{CO}_{2}<-2 \mathrm{~K}$ & 0.32 & 0.52 & 0.86 & 1.31 \\
window minus $\mathrm{CO}_{2}<-4 \mathrm{~K}$ & 0.10 & 0.27 & 0.27 & 0.54 \\
window minus $\mathrm{CO}_{2}<-6 \mathrm{~K}$ & 0.02 & 0.08 & 0.09 & 0.21 \\
\hline
\end{tabular}

$\mathrm{WTP}=$ Western Tropical Pacific (defined here as the region between latitude $15^{\circ} \mathrm{S}$ and $15^{\circ} \mathrm{N}$, longitude $100^{\circ} \mathrm{E}$ to $180^{\circ} \mathrm{E}$ );

$\mathrm{TO}=$ tropical ocean exclusive of the WTP;

window $=$ bt 1231 ;

$\mathrm{CO}_{2}=\mathrm{bt} 712$;

$\mathrm{H}_{2} \mathrm{O}=$ bt1419.
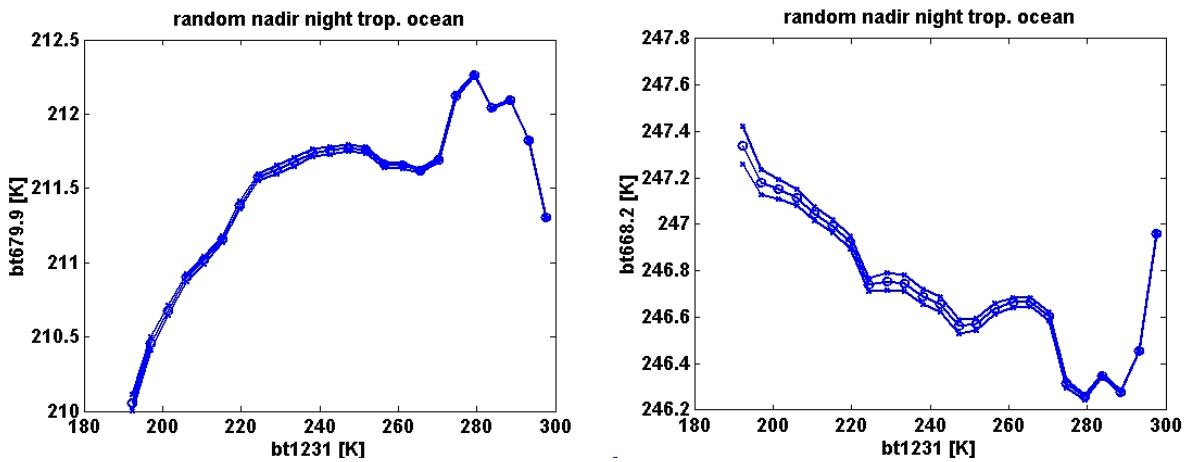

Fig. 4a. Scatter diagram of temperatures above the tropopause as function of bt1231 near $40 \mathrm{hPa}$ (left) and near $2 \mathrm{hPa}$ (right) using AIRS channels.

summarizes the rain rate for $\mathrm{CC}$ identified by inverted spectra as function of DT for the WTP and the tropical ocean (TO) exclusive of the WTP.

\section{Model calculations}

The observed brightness temperatures allow a physical interpretation of the height of the cloud tops relative to the height of the tropopause. We used model calculations for 34 profiles from a combination of two data sets: (1) the set of regression profiles (including the Air Force Geophysical Laboratory (AFGL) profiles used by Strow et al. (2003) to make the AIRS Fast Model Radiative Transfer Algorithm (RTA), and
(2) supplemented by profiles from the TIGR3 (1999) data base. The intent in the selection of the profiles was to cover the dynamic range of tropical ocean profiles, not their much narrower statistical distribution. The chosen profiles had a median tropopause pressure of $90 \mathrm{hPa}$ (ranging from 56 to $125 \mathrm{hPa}$, with $83 \mathrm{hPa}$ and $103 \mathrm{hPa}, 16$ and $84 \%$ tile, respectively), and a median cold point temperature $197 \mathrm{~K}$ (ranging $185 \mathrm{~K}$ to $207 \mathrm{~K}, 193 \mathrm{~K}$ and $202 \mathrm{~K}, 16$ and $84 \%$ tile, respectively). The tropopause was defined by the coldest point in the profiles. For each model profile we simulated the spectra for optically thick cirrus clouds, with the effective diameter of the ice particles being 20, 30 and 50 microns. Iwasaki et al. (2010) used 30 micron particles. In the model calculations 
Table 2. Summary of rain rates and 10 micron window slopes (DC $=$ bt961-bt790) under random near nadir conditions and as function of DT.

\begin{tabular}{lrrrr}
\hline & Day TO & Night TO & Day WTP & Night WTP \\
\hline Rain rate & & & & \\
(DT $<-2$ K condition) mean $[\mathrm{mm} / \mathrm{hr}]$ & 3.94 & 5.73 & 3.21 & 3.82 \\
Random condition mean [mm/hr] & 0.12 & 0.13 & 0.20 & 0.25 \\
bt1231 1\%tile/99\%tile [K] (DT $<-2 \mathrm{~K})$ & $190-208$ & $188-207$ & $190-207$ & $190-208$ \\
\hline $\begin{array}{l}\text { (bt961-bt790) [K] } \\
\text { Mean (DT }<0 \text { K condition) }\end{array}$ & 1.20 & 1.11 & 1.29 & 1.24 \\
Mean (DT $<-2$ K condition) & 1.08 & 0.97 & 1.12 & 1.11 \\
Mean (DT $<-4$ K condition) & 0.98 & 0.82 & 0.86 & 0.99 \\
Mean (DT $<-6$ K condition) & 0.84 & 0.82 & 0.76 & 0.73 \\
Stdev K & 0.67 & 0.63 & 0.70 & 0.67 \\
\hline
\end{tabular}

$\mathrm{WTP}=$ Western Tropical Pacific (defined here as the region between latitude $15^{\circ} \mathrm{S}$ and $15^{\circ} \mathrm{N}$, longitude $100^{\circ} \mathrm{E}$ to $180^{\circ} \mathrm{E}$ ); $\mathrm{TO}=$ tropical ocean exclusive of the WTP.
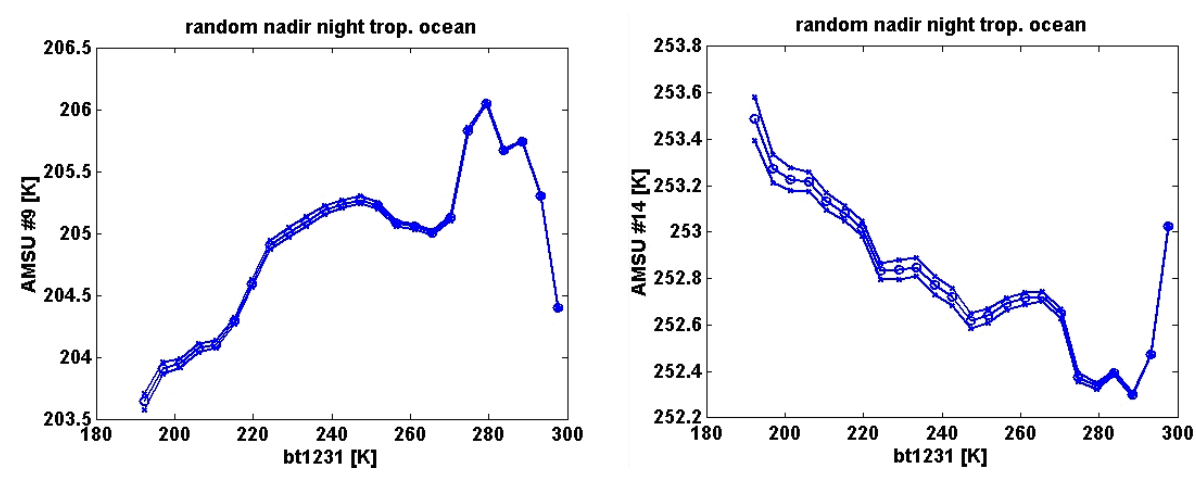

Fig. 4b. Scatter diagram of temperatures above the tropopause as function of bt1231 for the same footprints as Fig. $4 \mathrm{a}$, near $50 \mathrm{hPa}$ (left) and near $2 \mathrm{hPa}$ (right) using AMSU channels. Only the scatter diagram ridges and the PE lines are shown.

the cloud top pressure was increased in $20 \mathrm{hPa}$ steps from $120 \mathrm{hPa}$ below to $60 \mathrm{hPa}$ above the tropopause pressure. The only concession to the fact that the local tropopause height has little to say about the acceptable range of cloud top height was to exclude models with cloud top pressure smaller than $30 \mathrm{hPa}$. Using a tropopause at $100 \mathrm{hPa}$ as example, calculations were performed with the cloud tops at $40,60,80$, $100,120,140,160,180,200$ and $220 \mathrm{hPa}$, assuming the temperature of the clouds particles was given by the temperature profile. The amount of cirrus ice was distributed in the RTA per the layer average pressure. The scattering part of the RTA used the Parametrization of Cloud Longwave Scattering for Atmospheric Modeling (PCLSAM) algorithm by Chou et al. (1999). Ice aggregate scattering parameters were based on Baran (2003). The Ice Water Content (IWC) of $5 \mathrm{~g} / \mathrm{m}^{3}$ was selected to approximate the mean observed DC under DT $<-2 \mathrm{~K}$ conditions. This number is larger than that determined by Iwasaki et al. (2010), as they studied the sub visible cirrus blown off the top of a deep convective cloud, while in this paper we are more interested in studying the overall characteristics of optically thick CC. The cloud bottom pressure in the model was set $150 \mathrm{hPa}$ lower than the cloud top pressure, corresponding to $3-5 \mathrm{~km}$ thick clouds. This assumption is not critical since the clouds become optically thick within $20 \mathrm{hPa}$ of the cloud top in all cases.

Figure $2 b$ shows the results of the model calculation DT vs. bt1231 while Fig. 3 b shows DC $=$ bt $961-b t 790$ vs. DT. In both cases the calculations use 30 micron particles. Model spectra for three distinct groups are shown in Figs. $2 b$ and $3 b$ : (1) 77 cloud tops more than $5 \mathrm{hPa}$ above the tropopause are shown with a blue " $x$ ". (2) 30 within $5 \mathrm{hPa}$ of the tropopause are shown with a red "+", and (3) 204 more than $5 \mathrm{hPa}$ below the tropopause are shown with a green "o", respectively. The models with 20 and 50 micron effective particle sizes look very similar. With 20,30 , and 50 micron effective particle sizes, DC for cloud tops below the tropopause (green) increases from $1.6 \mathrm{~K}$ to $2.0 \mathrm{~K}$ to $2.5 \mathrm{~K}$, but the clear separation between the blue, red and green cloud tops is unchanged. 


\section{Discussion}

\subsection{Spectral identification and characterization of cold clouds}

Table 1 shows that $3 \%$ of the spectra from the tropical oceans, and almost 7\% in the WTP, are associated with cloud tops colder than $225 \mathrm{~K}$. An order of magnitude smaller fraction of these clouds, almost exclusively with bt $1231<210 \mathrm{~K}$, can be identified by their inverted spectra. We refer to cloud tops which satisfy the DT $<0 \mathrm{~K}$ and $\mathrm{DT}<-2 \mathrm{~K}$ condition in the following as DCCi and DCCi2, respectively. Historically, these spectral inversions were first noted as negative brightness temperature differences between the GOES $11 \mu \mathrm{m}$ window and $6.7 \mu \mathrm{m}$ water channels (Ackerman, 1996). The observed brightness temperatures are essentially the temperature where the combined opacity of the atmosphere and the clouds reaches an optical depth of one. For clouds well below the tropopause and for channels with strong water vapor or $\mathrm{CO}_{2}$ sensitivity, optical depth unity is reached well above the cloud top, while the window channel reaches unit optical depth very close to the cloud top temperature. In this case the difference between the window channel and a water or $\mathrm{CO}_{2}$ channel is positive. As the cloud tops reach closer to the tropopause, the integrated column amount of water and $\mathrm{CO}_{2}$ decreases steeply. As the cloud top reaches close to the tropopause, the absorption in the water vapor or $\mathrm{CO}_{2}$ channel between the cloud top and the tropopause balances the emission above the tropopause (the green spectrum in Fig. 1b). For strong water or $\mathrm{CO}_{2}$ channels this occurs for cloud tops very close to the tropopause. For cloud tops above this level the spectra are inverted. Either strong $\mathrm{CO}_{2}$ or water lines could be used to identify this inversion, but not ozone lines, since most of the ozone is in the stratosphere. A rough equivalent of the $6.7 \mu \mathrm{m}$ water channel for AIRS is the channel at $1419 \mathrm{~cm}^{-1}$. Under tropical clear conditions the weighting function of the water channel due to water vapor absorption peaks near $200 \mathrm{hPa}$. If we define DW =bt1231bt1419, then DW ranges, or DW $=1231$-water, DW ranges from +53 to $+75 \mathrm{~K}$ under tropical ocean clear conditions, depending on the details of the temperature and water vapor profile. However, water is a function of temperature and water vapor mixing ratio in the atmospheric column. Observations that strong convection "moistens" the upper troposphere (Ray and Rosenlof, 2007) and speculations that strong convection may result in injection of water vapor into the stratosphere potentially complicate the interpretation of inverted water vapor spectra based on a DW threshold. This concern is largely eliminated by using $\mathrm{CO}_{2}$ absorption, since the $\mathrm{CO}_{2}$ mixing ratio is not likely to be a significant function of strong convection. We use the strong $\mathrm{CO}_{2}$ absorbing line at $712 \mathrm{~cm}^{-1}$. DT $=$ bt1231-bt712 ranges from 55 to $62 \mathrm{~K}$ under tropical ocean clear conditions. Table 1 includes cold cloud frequencies as function of DT and DW. The frequency of inverted spectra identified with equivalent DT and

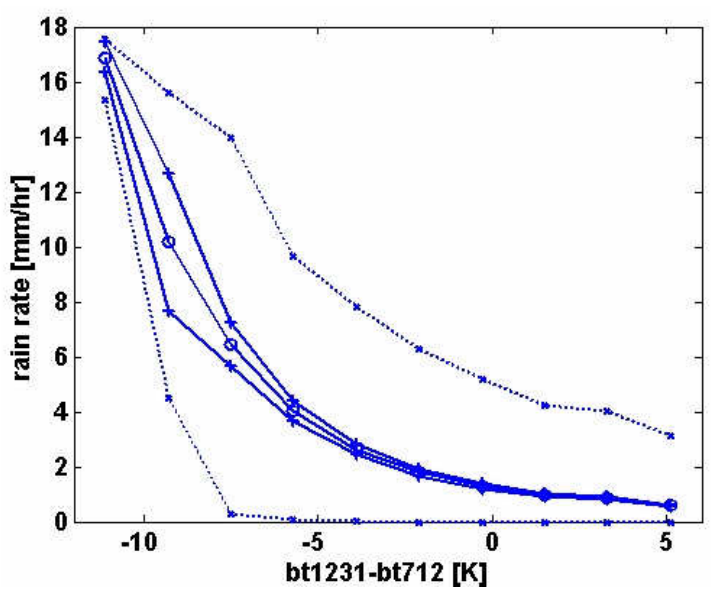

Fig. 5. Rain rate as function of $D T=b t 1231-b t 712$. The ridge line (o) and its probable error $(+)$ are the solid lines. The dotted lines, which connect the 16 and 84 percentile values of the data within each bin, give an indication of the scatter in the data.

DW thresholds is similar due to the similarity of the bt712 and water weighting functions. In the following we use a DT threshold to identify inverted spectra.

While DCCi can be identified using the difference between just two infrared channels, DT, the characterization of the physical conditions and the cloud top altitude relative to the tropopause requires additional channels available with a hyperspectral sounder. The exploitation of the gradient across the 10 micron window channel has been used to characterize cloud properties for many years (e.g. Inoue, 1987, who used the difference between the $11 \mu \mathrm{m}$ and $12 \mu \mathrm{m}$ HIRS window channels on NOAA-7). In the case of AIRS we have many window channels in a much larger spectral region, which can be used for the characterization of cirrus clouds (e.g. Kahn et al., 2008). We focus on three window channels. For a water/ice cloud, the cloud optical depth increases slowly going from $1231 \mathrm{~cm}^{-1}(8.1 \mu \mathrm{m})$ to $961 \mathrm{~cm}^{-1}(10.4 \mu \mathrm{m})$, but increases steeply from there to $790 \mathrm{~cm}^{-1}(12.6 \mu \mathrm{m})$. The $790 \mathrm{~cm}^{-1}$ channel reaches optical depth unity sooner (penetrates less into the cloud) than the $961 \mathrm{~cm}^{-1}$ channel or the $1231 \mathrm{~cm}^{-1}$ channel. Since the lapse rate below the tropopause is negative, bt790 measures a lower temperature than bt 1231 , as much as $20 \mathrm{~K}$. We already defined DC = bt961-bt790. Since the optical depth is strongly cloud particle size, shape and integrated amount dependent, a quantitative interpretation of observed DT and DC requires scattering model calculations, discussed in the following section.

\subsection{Model spectra and observation comparison}

Figure $2 \mathrm{~b}$ shows that virtually all cloud tops identified with bt1231 between $210 \mathrm{~K}$ and $225 \mathrm{~K}$ or DT $>0$ are well below the tropopause and may be optically thick cirrus clouds or 
anvil clouds. On the other hand, cloud tops colder than $200 \mathrm{~K}$ are virtually all associated with inverted spectra. Figures $2 \mathrm{~b}$ and $3 b$ show that the DT $<-2 \mathrm{~K}$ threshold fairly cleanly separates the cloud tops more than $5 \mathrm{hPa}$ below the tropopause from the higher clouds. The additional $\mathrm{DC}>0.5 \mathrm{~K}$ test (Fig. 3b) separates the clouds more than $5 \mathrm{hPa}$ above (blue) from those more than $5 \mathrm{hPa}$ below the tropopause (green). The opacity of the ice clouds at $790 \mathrm{~cm}^{-1}$ is larger than the opacity at $961 \mathrm{~cm}^{-1}$, i.e. the $790 \mathrm{~cm}^{-1}$ channel penetrates into the cloud for a smaller distance before the cloud become optically thick. If the cloud top is below the tropopause, bt790 is colder than bt 961 , i.e. DC $>0 \mathrm{~K}$, if the cloud top is above the tropopause then $\mathrm{DC}<0 \mathrm{~K}$. The window channel difference $\mathrm{DC}=$ bt961-bt790 therefore allows a separation between cloud tops above and below the tropopause. Table 2 includes a summary of DC as function of DT.

The comparison of Fig. 2a and b shows similarities between the observations and the model spectra in the slope as function of bt1231. However, the observations come to a sharp point at bt $1231=180 \mathrm{~K}, \mathrm{DT}=-12 \mathrm{~K}$, while the blunt tip of the scatter diagram for the models is filled with cloud tops near and above the tropopause. This is the first indication that the observations contain few if any cloud tops more than $5 \mathrm{hPa}$ above the tropopause. This is confirmed in the comparison of the data in Fig. 3a and the model in Fig. 3b: Very few of the observed cloud tops have $\mathrm{DC}<0$. The mean DC for clouds which satisfy the (DT $<-2 \mathrm{~K}$ ) conditions is $+1 \mathrm{~K}$ with standard deviation of $0.65 \mathrm{~K}$ (Table 2), but is close to $2 \mathrm{~K}$ for lower cloud tops. The analysis of $\mathrm{DC}<0$ observations has to include observational noise considerations. The noise in DC due to detector noise alone is $0.5 \mathrm{~K}$, i.e. the few observations with $\mathrm{DC}<0$ are consistent with random noise. Figures $2 \mathrm{~b}$ and $3 \mathrm{~b}$ show model calculation using 30 micron effective particle size. For lower (warmer) cloud tops $(0<\mathrm{DT}<5 \mathrm{~K})$ the models show little change in $\mathrm{DC}(\mathrm{DC}=+2 \mathrm{~K})$, while the observations show a gradient (from $\mathrm{DC}=1.5 \mathrm{~K}$ to $\mathrm{DC}=2 \mathrm{~K}$ ). We attribute this difference to the simplification of using a fixed IWC, particle size and ice crystal habit for all models, including clouds well below the tropopause. Particle sizes are expected to diminish with height, as well as change structure. We conclude that clouds identified with the simple DT $<-2 \mathrm{~K}$ threshold, referred to as DCCi2, are within a few hPa of the tropopause.

\subsection{Penetrating convection}

The observation of inverted spectra has been taken as evidence of Overshooting Convection (OC, e.g. Schmetz et al., 1997), with the implication of tropopause penetration (Wang, 2007). The model calculations show that the inversion of spectra starts with cloud tops well below the tropopause. Figure 4a shows that the temperature structure in the lower stratosphere becomes increasingly distorted as the cloud top temperature drops below $230 \mathrm{~K}$. In the presence of strong convection the tropopause is unusually cold. Since this ef- fect is seen independently in the AIRS and AMSU brightness temperatures, it is not a high cloud artifact or an artifact of a retrieval algorithm. This effect can be visualized as a localized cold (upward) bulge in the tropopause in the presence of strong convection, which allows cloud top to be colder than the temperature of the tropopause cold point derived from the analysis or reanalysis. This observation is consistent with the Gettelman et al. (2002) statement that a small fraction of cold clouds "appear to be colder than the mean tropopause". The only way this can happen is due to a local cold bulge caused by very strong convection, which is not represented in the reanalysis. OC overshoots the tropopause height in the reanalysis, but not the actual tropopause. However, convection transports water vapor, cirrus ice and pollutants into these bulges. We can now speculate as to what happens when the strong convection subsides and the bulges disappear: the material transported into the bulges equilibrates, but is now in the lower stratosphere. This is consistent with observations of transport of pollutants into the lower stratosphere in the presence of strong convection, e.g. Randel et al. (2010), without requiring literal tropopause penetration.

There is evidence in the literature that GOES brightness temperature images of cold cloud tops show fine structures with $5-10 \mathrm{~km}$ spatial scale, e.g. Bedka et al. (2009) finds very cold clouds just resolved with GOES and MODIS data protruding above large cold anvils. These clouds appear to be buoyant convective bubbles, referred to in the following as Protruding Convective Bubbles (PCBs), a few km higher than the surrounding cold anvil. With the assumption that the cold anvil reaches the tropopause, the top of a several km high PCB above the cloud top would imply stratosphere penetration. However, the linear combination of model data shows that cloud tops well below the tropopause with an imbedded PCB can have inverted spectra: assume the cloud top is at $150 \mathrm{hPa}$ (approximately $210 \mathrm{~K}$ ), i.e. about $50 \mathrm{hPa}$ (about $3 \mathrm{~km}$ ) below the tropopause, without a PCB. This is seen by AIRS as bt $1231=210 \mathrm{~K}$ and DT $=0 \mathrm{~K}$. Assume a $5 \mathrm{~km}$ diameter imbedded PCB, with the same composition as the anvil, reaches the tropopause. With a $5 \mathrm{~km}$ FOV this would be detected as a DT $=-10 \mathrm{~K}$ inverted spectrum, but averaged in the larger AIRS FOV it would appear as a bt $1231=201.5 \mathrm{~K}$ cloud, with a DT $=-1 \mathrm{~K}$. If PCBs were to penetrate several $\mathrm{km}$ into the stratosphere, the observable spectral inversion would decrease. For the DT $<-4 \mathrm{~K}$ conditions the entire anvil has to reach $200 \mathrm{~K}$ or several imbedded PCBs are required. We conclude that DCCi are consistent with cold clouds with imbedded PCBs, and what is referred to as OC appear to be PCBs that reach, but do not overshoot the local tropopause.

\subsection{Deep convection and storms}

Figure 5 shows the rain rate as function of DT. The rain rate increases steeply for $\mathrm{DT}<-2 \mathrm{~K}$ and even more at $\mathrm{DT}<-5 \mathrm{~K}$. There is considerable scatter in the observed 
rain rates, as can be seen from the 16 and $84 \%$-tile (dotted) lines in Fig. 5. For DT $-2 \mathrm{~K}, 16 \%$ of the DCCi2 were associated with zero rain rate. The most likely explanation for this is that even if DCCi2 exclusively identify deep convective clouds, there is no reason that any associated rain should be happening within minutes of the overpass of the EOS Aqua spacecraft. The DT $<-2 \mathrm{~K}$ threshold, which we use to define DCCi2 objects, identifies clouds associated with on average $3 \mathrm{~mm} / \mathrm{hr}$ rain rate (Table 2). DCCi2 therefore identify the presence of active Deep Convection without the need for explicit rain rate measurements. With this definition, DCCi2 approximate the definition of Deep Convection as $1 \times 1^{\circ}$ lat/lon areas associated with rain rates of more than $1.6 \mathrm{~mm} / \mathrm{hr}$ (Zelinka and Hartmann, 2009) using microwave measurements.

The literature contains few references to DCC in the tropical oceans and their possible relationship to severe storms. Based on the relative lack of lightning activity and Precipitation Features (PF) over ocean, Liu and Zipser (2005) argued that high clouds identified by their low brightness temperatures in IR window channels are associated with storms much weaker than their land counterparts. Based on our analysis this is what one should expect, since a simple IR threshold can not separate deep convective clouds from the multitude of cold anvil clouds. This separation is accomplished by the spectral inversion. The association between severe storms, including torrential rain and hail over land with cloud top temperatures colder than $210 \mathrm{~K}$ in the $11 \mu \mathrm{m}$ GOES window channel goes back to Reynolds (1980). A number of papers (e.g. Adler et al., 1985; Brunner et al., 2007) have associated OC detected with GOES with severe storms and strong horizontal and vertical wind shear. Bedka et al. (2009) used five years of GOES-12 and MODIS data for the Gulf Stream and the US Great Plains to show the strong relationship between OC, aviation turbulence and lightening activity. Setvak et al. (2008) studied deep convective storms over Europe using Meteosat Second Generation (MSG) Spinning Enhanced Visible and InfraRed Imager (SEVIRI) data and found an excellent correlation with inverted spectra utilizing the brightness temperature difference between the $10.8 \mu \mathrm{m}$ and the $6.2 \mu \mathrm{m}$ bands. Conceptually this approach is similar to our use of DW. Based on the association between severe storms over land and inverted spectra and the association of DCCi2 with high rain rates we conclude that DCCi2 in the tropical oceans are associated with severe storms. Long-term trends in the statistical properties of DCCi2 could therefore be an interesting metric of climate change.

While the analysis of the physical conditions related to cold clouds requires many hyperspectral infrared channels and simultaneous microwave sounding and rain rate data, the identification of DCCi2 requires only one good window channel, e.g. the bt1231 channel, and one good strong $\mathrm{CO}_{2}$ absorbing channel, e.g. the bt712 channel. The exclusive use of infrared channels allows the identification of deep convection and associated severe storms with the high spatial resolution available in the infrared. However, the brightness temperature differences found with the broad spectral passbands used by current sounders is small, making threshold identifications of DCC sensitive to instrumental noise. Setvak et al. (2008), using SEVIRI data, shows no differences larger then $4 \mathrm{~K}$ with a $3 \mathrm{~km}$ FOV, while with the high spectral resolution of AIRS, but with a much larger FOV, we observed DW (and DT) up to $13 \mathrm{~K}$. This suggests that improved identification of severe storms with future advanced geostationary satellites can be accomplished using just one high spectral resolution infrared channel, without the need for full coverage of the entire IR spectrum or microwave data.

\section{Conclusions}

Data from AIRS on the EOS Aqua spacecraft each day show tens of thousands of cold clouds in the tropical oceans with $10 \mu \mathrm{m}$ window channel brightness temperatures colder than $225 \mathrm{~K}$. These clouds represent a mix of cold anvil clouds and deep convective clouds (DCC). This mix can be separated by noting that the difference between two channels, a window channel and a channel with strong $\mathrm{CO}_{2}$ absorption, is negative for some cold clouds, i.e. the spectra for some cold clouds are inverted. We refer to cold clouds with more than $2 \mathrm{~K}$ inverted spectra as DCCi2. Associated with DCCi2 is a very high mean rain rate and a local upward displacement of the tropopause, a cold "bulge", which can be seen directly in the brightness temperatures of AIRS and AMSU temperature sounding channels in the lower stratosphere. The very high rain rate and the local distortion of the tropopause indicated that DCCi2 object are associated with severe storms. Significant long-term trends in the statistical properties of DCCi2 could be interesting indicators of climate change. While the analysis of the physical conditions related to DCCi2 requires hyperspectral infrared and microwave data, the identification of DCCi2 requires only one good window channel and one strong $\mathrm{CO}_{2}$ sounding channel. This suggests that improved identification of severe storms with future advanced geostationary satellites could be accomplished with the addition of just one strong $\mathrm{CO}_{2}$ sounding channel, without the need for full coverage of the entire IR spectrum or microwave data.

Acknowledgements. The research described in this paper was carried out at the Jet Propulsion Laboratory, California Institute of Technology, under a contract with the National Aeronautics and Space Administration, and at UMBC, supported by NASA HQ. We are grateful for the long-term support of Ramesh Kakar, Aqua Program Scientist at NASA HQ and helpful comments by Tim Dunkerton.

Edited by: T. J. Dunkerton 


\section{References}

Ackerman, S. A.: Global satellite observations of negative brightness temperature differences between 11 and 6.7 microns, J. Atmos. Sci., 53, 2803-2812, 1996.

Adler, R. F., Markus, M. J., and Fen, D. D.: Detection of severe Midwest Thunderstorms using Geosynchronous Satellite Data, Mon. Weather Rev., 113, 769-781, 1985.

Aumann, H. H., Chahine, M. T., Gautier, C., Goldberg, M., Kalnay, E., McMillin, L., Revercomb, H., Rosenkranz, P. W., Smith, W. L., Staelin, D. H., Strow, L., and Susskind, J.: AIRS/AMSU/HSB on the Aqua Mission: Design, Science Objectives, Data Products and Processing Systems, IEEE T. Geosci. Remote, 41.2, 253264, 2003.

Aumann, H. H., Broberg, S., Elliott, D., Gaiser, S., and Gregorich, D.: Three years of Atmospheric Infrared Sounder radiometric calibration validation using sea surface temperatures, J. Geophys. Res., 111, D16S90, doi:10.1029/2005JD006822, 2006.

Baran, A. J.: Simulation of infrared scattering from ice aggregates by use of a size-shape distribution of circular ice cylinders, Appl. Optics, 42, 2811-2818, 2003.

Bedka, K., Brunner, J., Dworak, R., Feltz, W., Otkin, J., and Greenwald, T.: Objective Satellite-based Overshooting Top Detection Using Infrared Window Channel Brightness Temperature Gradients, J. Appl. Meteor. Climatol. 49, 181-202, doi:10.1175/2009JAMC2286.1, 2009.

Brunner, J. C., Ackerman, S. A., Bachmeier, A. S., and Rabin, R. M.: A quantitative Analysis of the Enhanced-V Feature in Relation to Severe Weather, Wea. Forecasting, 22, 853-872, 2007.

Chou, M.-D., Lee, K.-T., Tsay, S.-C., and Fu, Q.: Parameterization for cloud longwave scattering for use in Atmospheric Models, J. Climate, 12, 159-169, 1999.

Elliott, D. E, Aumann, H. H., Strow, L. L., and Gregorich, D. T.: Contributions to Climate Studies from four years of hyperspectral data from the Atmospheric Infrared Satellite (AIRS). Proc. SPIE., 6677, J.J. Butler and J. Xiong Editors, 2007.

Gettelman, A., Salby, M. L., and Sassi, F.: The distribution and influence of convection in the tropical tropopause region, J. Geophys. Res., 107(D10), 4080, doi:10.1029/2001JD001048, 2002.

Imaoka, Keiji, Kachi, Misako, Shibata, Akira, Kasahara, Marehito, Iida, Yukiei, Tange, Yoshio, Nakagawa, Keizo, and Shimoda, Haruhisa: Five years of AMSR-E monitoring and successive GCOM-W1/AMSR2 instrument, Proceedings of the SPIE, 6744, doi:10.1117/12.740366, 2007.

Inoue, T.: A Cloud Type Classification With NOAA 7 SplitWindow Measurements, J. Geophys. Res., 92(D4), 3991-4000, 1987.

Iwasaki, S., Shibata, T., Nakamoto, J., Okamoto, H., Ishimoto, H., and Kukota, H.: Characteristics of deep convection measured by the A-train constellation, J. Geophys. Res., 115, D06201, doi:10.1029/2009JD013000, 2010.
Kahn, B. H., Liang, C. K., Eldering, A., Gettelman, A., Yue, Q., and Liou, K. N.: Tropical thin cirrus and relative humidity observed by the Atmospheric Infrared Sounder, Atmos. Chem. Phys., 8, 1501-1518, doi:10.5194/acp-8-1501-2008, 2008.

Kalnay, E. M., Kanamitsu, M., Kistler, R., Collins, W., Deaven, D., Gandin, L., Iredell, M., Saba, S., White, G., Woolen, J., Zhu, Y., Chelliah, M., Ebisuzaki, W., Higgins, W., Janowiak, J., Mo, K. C., Ropelewski, C., Wang, J., Leetmaa, A., Reynolds, R., Jenne, R., and Joseph, D.: The NCEP/NCAR 40 year reanalysis project, B. Am. Meterolol. Soc., 77, 437-471, 1996.

Lambrigtsen, B. H.: "Calibration of the AIRS Microwave Instruments”, IEEE T Geosci. Remote, 41.2, 369-378, 2003.

Liu, C. and Zipser, E. J.: Global distribution of convection penetrating the tropical tropopause, J. Geophys. Res, 110, D23104, doi:10.1029/2005JD006063, 2005.

Randel, J. W., Park, M., Emmons, L., Kinnison, D., Bernath, P., Walker, K. A., Boone, C., and Pumphrey, H.: Asian Monsoon Transport of Pollution to the Stratosphere, Science, 328, 611613, doi:10.1126/science.1182274, 2010.

Ray, E. A. and Rosenlof, K. H.: Hydration of the upper tropopause by tropical cyclones, J. Geophys. Res., 112, D12311, doi:10.1029/2006JD008009, 2007.

Reynolds, D. W.: Observations of Damaging Hailstorms from Geosynchronous Satellite Digital Data, Mon. Weather Rev., 108, 337-348, 1980.

Romps, D. M. and Kuang, Z.: Overshooting Convection in tropical cyclones, Geophys. Res. Lett., 36, L09804, doi:10,1029/2009GL037396, 2009.

Schmetz, J., Tjemkes, S. A., Gube, M., and van de Berg, L.: Monitoring deep convection and convective overshooting with METEOSAT, Adv. Space Res., 19(3), 433-441, 1997.

Setvák, M., Lindsey, D. T., Rabin, R. M., Wang, P. K., and Demeterova, A.: Indication of water vapor transport into the lower stratosphere above midlatitude convective storms: Meteosat Second Generation satellite observations and radiative transfer model simulations, Atmos. Res., 89, 170-180, 2008.

Strow, L. L, Hannon, S., DeSouza-Machado, S., Tobin, D., and Motteler, H.: An overview of the AIRS Radiative Transfer Model, IEEE T. Geosci. Remote, 41, 303-313, 2003.

TIGR3: A large collection of RAOBs available from Laboratoire de Meteorologie Dynamique (LMD), France, 1999.

Walden, V. P., Roth, W. L., Stone, R. S., and Halter, B.: Radiometric Validation of the AIRS Infrared Sounder over the Antarctic Plateau, J. Geophys. Res., 111, D09S03, doi:10.1029/2005JD006357, 2006.

Wang, P.: The thermodynamic structure atop a penetrating convective thunderstorm, Atmos. Res., 83, 254-262, 2007.

Wilheit, T., Kummerow, C. D., and Ferraro, R.: Rainfall Algorithms for AMSRE, IEEE T. Geosci. Remote, 41.2, 204-214, 2003.

Zelinka, M. and Hartmann, D. L.: Response of Humidity and Clouds to Tropical Deep Convection, J. Climate, 22, 2389-2404, doi:10.1175/2008JCLI2452.1, 2009. 